\title{
Erratum to: Effects of Hypoxia on Fish Survival and Oyster Growth in a Highly Eutrophic Estuary
}

\author{
Rikke Jeppesen $^{1}$ • Miguel Rodriguez ${ }^{1}$ - Jenna Rinde ${ }^{1,2}$ • John Haskins ${ }^{1}$. \\ Brent Hughes ${ }^{1,3,4}$ - Laura Mehner ${ }^{1}$ - Kerstin Wasson ${ }^{1,3}$
}

Published online: 23 February 2017

(C) Coastal and Estuarine Research Federation 2017

\section{Erratum to: Estuaries and Coasts}

\section{DOI 10.1007/s12237-016-0169-y}

The first sentence in the Discussion section of the original article was incomplete. Several words inadvertently disappeared during production. The corrected sentence is as follows and the original article was corrected as reflected in this erratum:

Our investigation revealed that water quality in four of the six wetlands examined was so degraded that it lead to negative responses even in estuarine indicator species known to be highly tolerant.

The online version of the original article can be found at http://dx.doi.org/ 10.1007/s12237-016-0169-y.

Rikke Jeppesen

rikke@elkhornslough.org

1 Elkhorn Slough National Estuarine Research Reserve, Watsonville, CA, USA

2 California State University, Monterey Bay, Seaside, CA, USA

3 Ecology and Evolutionary Biology, University of California, Santa Cruz, Santa Cruz, CA, USA

4 Division of Marine Science and Conservation, Nicholas School of the Environment, Duke University, Beaufort, NC, USA 